\title{
Screening for refractive errors in 6-9 month old infants by photorefraction
}

\author{
J. ATKINSON, ${ }^{1}$ O. J. BRADDICK, ${ }^{1}$ K. DURDEN, ${ }^{1}$ P. G. WATSON, ${ }^{2}$ \\ AND S. ATKINSON ${ }^{3}$ \\ From the ${ }^{1}$ Visual Development Unit, Department of Experimental Psychology, University of Cambridge; \\ ${ }^{2}$ Addenbrooke's Hospital, Cambridge; añd the ${ }^{3}$ Department of Community Medicine, Bristol and \\ Weston Health Authority
}

SUMMARY The method of isotropic photorefraction has been used in a trial of refractive screening of 6-9 month old infants. Data are presented on the calibration of the method against retinoscopic measurements and its reliability. In photorefractive screening of 1096 infants under cyclopentolate cycloplegia $5 \%$ were found to be hypermetropic (over $+3.5 \mathrm{D}$ ), $4.5 \%$ myopic, and $1.3 \%$ anisometropic (over $1 \mathrm{D}$ ). These refractive errors were confirmed on retinoscopic follow-up (with the exception of a few anisometropes). Follow-up of controls shows that one small refractive error was missed in 52 infants. We conclude that photorefraction is a valid and practical screening technique. Longitudinal study of infants with refractive errors will assess the value of early detection, in particular for prediction and prevention of strabismus.

The commonest preschool vision problems at the present time are strabismus and amblyopia. Estimates of their occurrence vary widely, ${ }^{1-7}$ with the average being somewhere about $5 \%$. This is a far higher incidence than that of more handicapping visual problems such as infant cataract, retinal pathologies, and neural defects, which affect much less than $1 \%$ of the preschool population. Consequently, cases of strabismus (both confirmed cases and pseudostrabismus) and amblyopia make up the majority of children attending ophthalmological clinics. There are not yet any generally accepted preventive measures to reduce the incidence of strabismus and amblyopia, and the success of treatment for such cases is very variable. $^{8}$

The data of Ingram et al. ${ }^{9}$ suggest that infants with a refraction of $+2.5 \mathrm{D}$ or more hypermetropia at age 1 year are 20 times more likely to develop strabismus and amblyopia than children with a more nearly emmetropic refraction. This raises the possibility that refractive screening of the population in infancy could identify children at risk of these disorders, and that early refractive correction might reduce that risk by reducing excessive accommodative convergence. ${ }^{10}$ Early refractive screening could also detect aniso-

Correspondence to Dr J. Atkinson, Department of Experimental Psychology, University of Cambridge, Downing Street, Cambridge CB2 3EB. metropia and any myopic errors that might significantly impair children's vision. However, the scarcity and expense of skilled retinoscopists on a large scale makes it unlikely that retinoscopic screening will be widely adopted in the near future.

We have developed a new method, isotropic photorefraction, which offers a means of refractive screening which can be carried out by paramedical personnel after a short training period, with apparatus and procedure that is rapid, reliable, and relatively inexpensive.

Pilot programmes for infant vision screening using this method are underway in Cambridge and in the Avon area. In this paper we describe the screening procedure and some results of the first 18 months of the Cambridge programme. (Data from Avon will be the subject of a separate report.) These results give an idea of the success of the programme in detecting early refractive problems; the outcome in terms of predicting and preventing strabismus and amblyopia will only be available from longer term follow-up, which is continuing.

\section{Materials and method}

\section{ISOTROPIC PHOTOREFRACTION}

The technique and theory of isotropic photorefraction are described in detail elsewhere. ${ }^{11-13}$ Here we will 


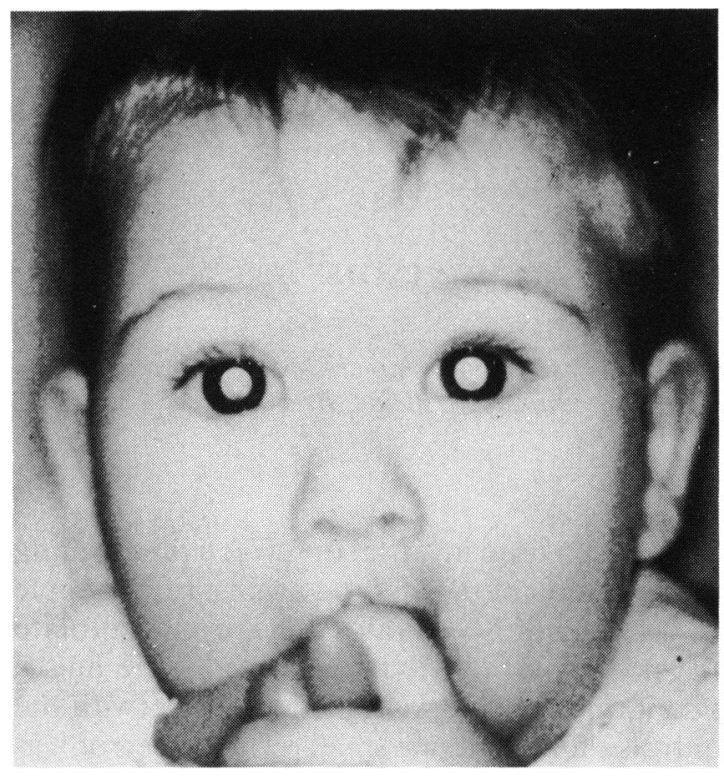

Fig. I Pupil photograph with the camera focused on the infant at $75 \mathrm{~cm}$.

describe the method only briefly, with information on its validation and calibration against other measures of refraction.

The isotropic photorefractor, a development of the earlier instrument of Howland and Howland, ${ }^{14}$ is a simple attachment to the wide-aperture $(\mathrm{f} / 1 \cdot 2,50$ $\mathrm{mm}$ ) lens of a standard $35 \mathrm{~mm}$ single-lens reflex

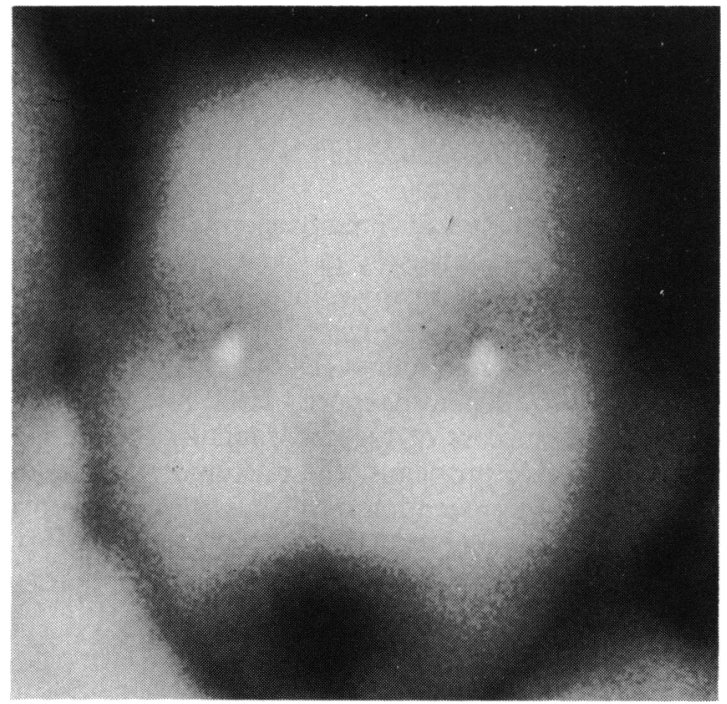

Fig. 2 Photorefractive image with the camera focused at $150 \mathrm{~cm}$ (camera-to-infant distance $75 \mathrm{~cm}$ ). Compare appearance of blur circles with Fig. 3.

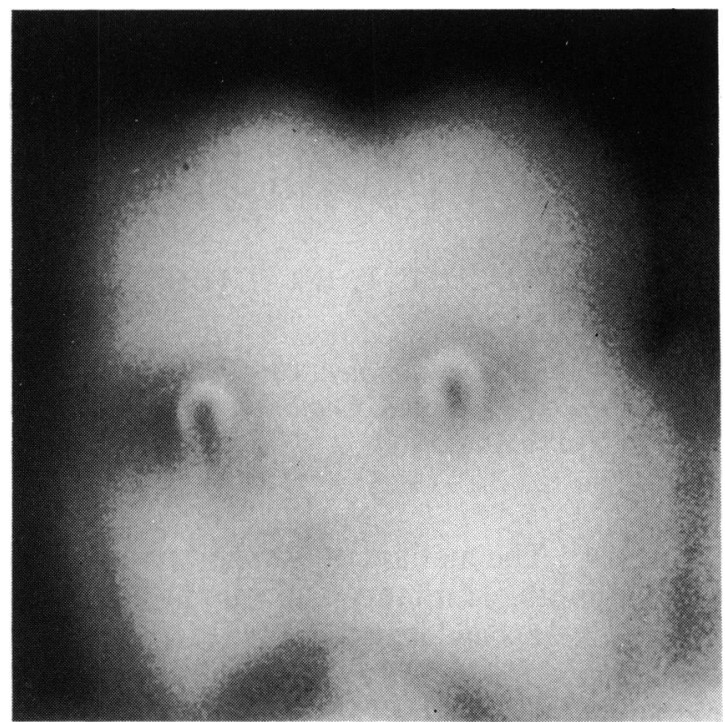

Fig. 3 Photorefractive image with the camera focused at 50 $\mathrm{cm}$ (camera-to-infant distance $75 \mathrm{~cm}$ ). Compared with the small, bright blur circles seen in Fig. 2; those seen with this setting are larger and more diffuse. This signifies that the infant is focused hypermetropically with respect to the camera distance. The size of the blur circles in Figs. 2 and 3 indicates that this error is small, i.e., this child has a emmetropic or small hypermetropic refraction, normal for this age.

camera. It consists of a fibreoptic light guide which delivers the light of an electronic flash along the optical axis of the camera to the eyes which are to be refracted. The light is reflected from the fundus of the eye so that the pupils appear brightly lit in the photograph. If the camera is defocused with respect to the patient's eyes, the reflected light appears as a blur circle on the photograph in the position of each eye. The size of each blur circle is a function of the eye's refractive state (and also depends on the size of the pupil). All the photographs discussed here were taken with the distance between patient and camera set at $75 \mathrm{~cm}$. In general 3 photographs are taken for each child. For each successful photograph the eyes refracted must be in line with the camera axis. This is brought about by the photographer always standing directly behind the camera and attracting the child's attention to a position close to the photorefractor.

In the first photograph of each set (Fig. 1) the camera is focused on the eyes ('pupil photograph'). This photograph allows measurement of the pupil size and inspection of the symmetry of the corneal reflexes. Two further photographs are taken (Figs. 2 and 3) with the camera focused at $150 \mathrm{~cm}$ and $50 \mathrm{~cm}$ (i.e., 0.67 dioptres in front and behind the child). A smaller blur circle in the second photograph (focus at 


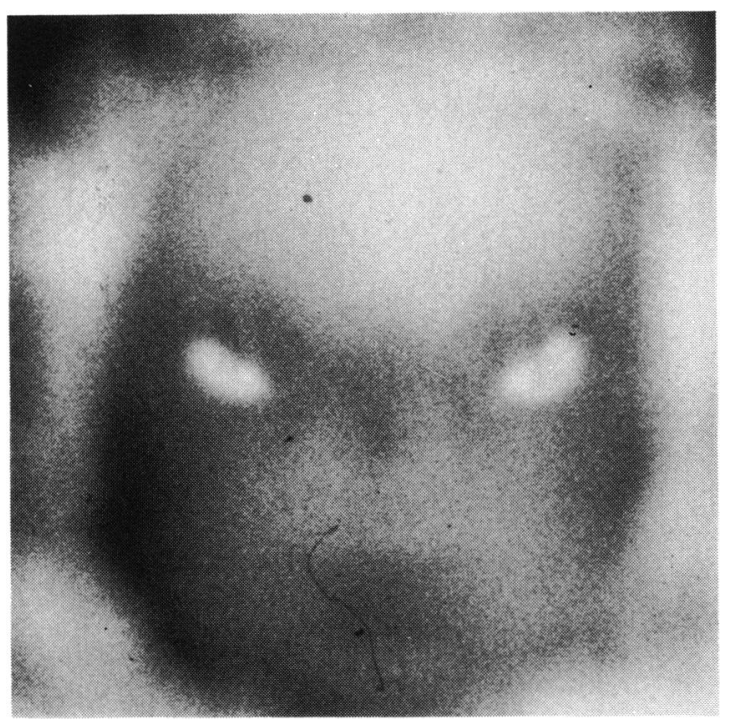

Fig. 4 Appearance of photorefractive blur images $(150 \mathrm{~cm}$ focus setting) for an astigmatic refraction. In this case the astigmatism is oblique.

$150 \mathrm{~cm}$ ) than in the third (focus at $50 \mathrm{~cm}$ ) is produced if the eyes are focused behind the camera (i.e., hypermetropically relative to the working distance of $75 \mathrm{~cm}$ ). If the blur circles are larger in the image with $150 \mathrm{~cm}$ focus than in the image with the $50 \mathrm{~cm}$ focus, the eyes are myopically focused with respect to the camera distance (i.e., at least $1.3 \mathrm{D}$ myopic). Because the blur circles for each eye are seen simultaneously, it is easy to check for differences between the eyes where the blur circles will be of different sizes. Astigmatism is apparent as an elongation of the blur circle (or rather, blur ellipse) along the axis of greatest defocus (Fig. 4).

The method may be used to study either the instantaneous position of focus of the actively accommodating eye, or (as here) the refraction of the eyes under cycloplegia.

\section{CALIBRATION OF PHOTOREFRACTION}

The size of the blur image produced from an eye with a given refractive error and pupil size may be theoretically predicted from computer ray tracing. ${ }^{13} \mathrm{We}$ used this procedure to construct tables from which the refractive error corresponding to a measured blur image size may be obtained. We have found the size of the blur circle on the photograph focused at $150 \mathrm{~cm}$ to be the most informative. This photograph was used for all the measurements to be discussed, and comparison with the photograph focused at $50 \mathrm{~cm}$ used only to determine the sign of the error (relative myopia or hypermetropia). Refractions derived by this procedure were compared with retinoscopic

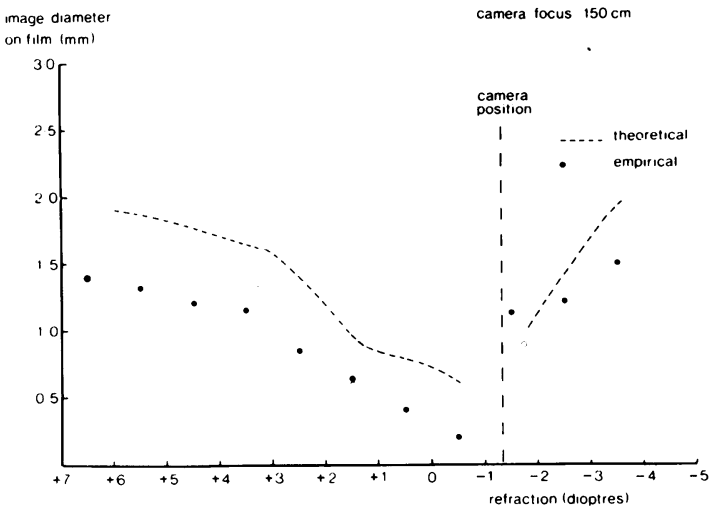

Fig. 5 Circles: measured size of photorefractive blur images for known refractions produced by an adult subject wearing a series of lenses under cycloplegia. Dotted line: size of images predicted by computer ray tracing. The empirical measures are smaller than the theoretical predictions, probably because the extreme outer regions of the light distribution are not measured.

refractions by Dr R. Ingram on a group of 383 infants. " The correlation between these 2 measures of refraction was high, but photorefractive estimates of hypermetropia were consistently lower (by 1.4 dioptres on average) than retinoscopic estimates from the same individuals. It is probable that the measured extent of the blur image as recorded on film is smaller than the extreme outer limit of the light distribution (which may be very faint) calculated by the ray tracing procedure, which would lead to underestimation of refractive errors. The discrepancy might also be due to a greater amount of accommodation by the infants when their attention is attracted for the photorefractive procedure (despite cyclopentolate cycloplegia). In any case an empirical calibration was desirable. This was done by photorefracting a series of adult subjects. Each of 7 individuals aged 25-39 years had one drop of $1 \%$ cyclopentolate hydrochloride administered to one eye and, after 40 minutes had elapsed for cycloplegia to take effect, was carefully refracted by retinoscopy. A subjective refraction was also obtained. A series of photorefractive pictures were taken with each subject's effective refraction varied by placing spectacle lenses ranging from -5 to +5 dioptres, in half-dioptre steps, in front of the eye. Measurements from these photographs were compared with the values predicted from the ray-tracing theory for the known refraction and for the individual's pupil size (pupil sizes under cycloplegia ranged from $7 \mathrm{~mm}$ to 9 $\mathrm{mm}$, sizes which are typical of infants photographed under cycloplegia in the screening programme). Fig. 


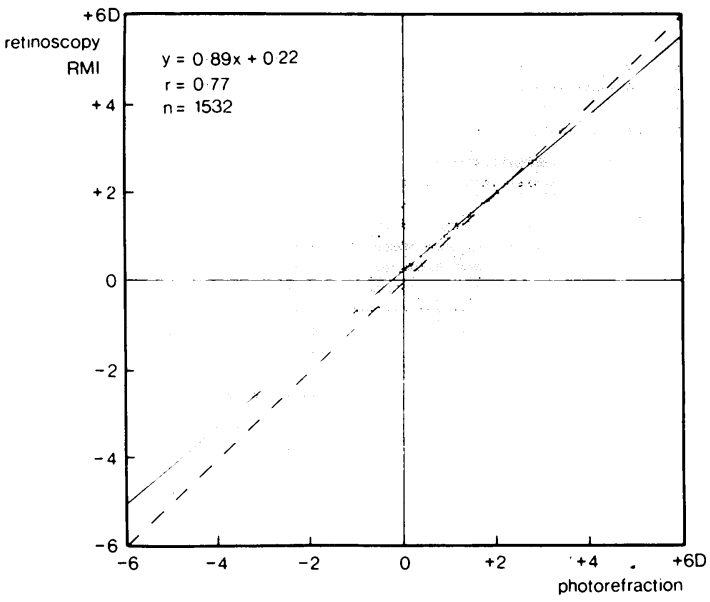

Fig. 6 Comparison of photorefraction measures (interpreted according to the empirical calibration) with retinoscopic refractions of 383 infants. Each point represents the results for one axis of one eye. The dashed line indicates exact equality, and the solid diagonal line is the best fitting linear relationship.

5 shows an example of the empirical and theoretical functions. From these comparisons a function relating empirical image size to theoretical image size was obtained, and used to convert the theoretical table into an empirically corrected table relating image size to refraction, as a function of pupil size. When this empirical table is used to obtain refractions from the photographed group of infants referred to above, the correlation with retinoscopic refraction is still high $(r=0.77)$, and now the absolute values of refraction obtained by the 2 methods are very close: mean refraction was $+1 \cdot 3 \mathrm{D}$ by photorefraction and $+1 \cdot 4$

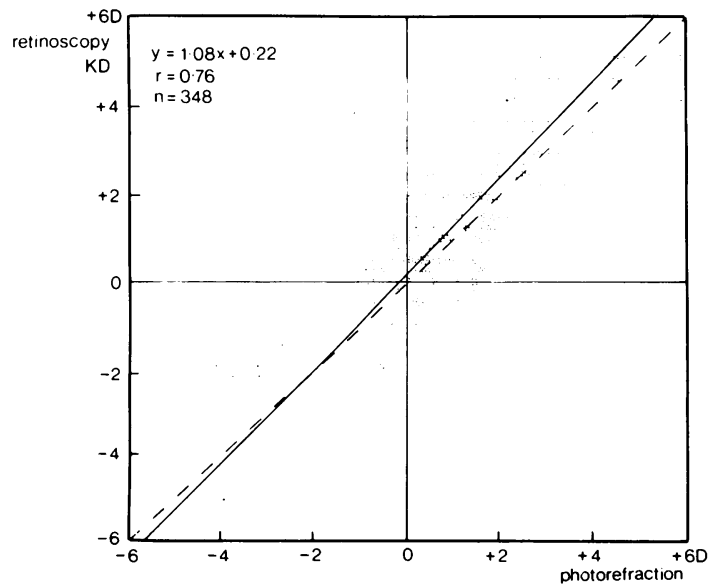

Fig. 7 As Fig. 6, comparing photorefraction with the results for a different retinoscopist on 83 infants.

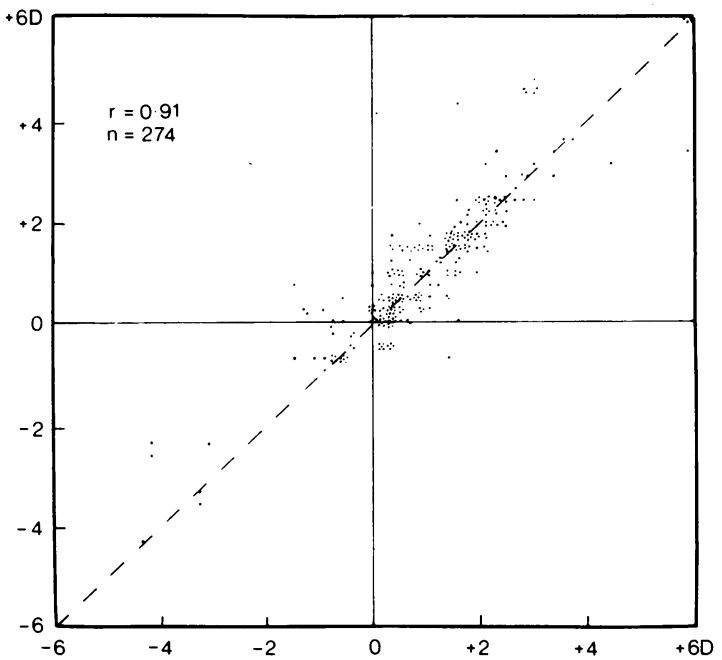

Fig. 8 Reliability of photorefraction. Each point represents the comparison of 2 independent photorefractive measurements on the same eye (from 69 infants).

D by retinoscopy. Fig. 6 shows the comparison of individual refractive measurements by the 2 methods. Fig. 7 shows a similar comparison with refractions of a different group of 83 infants by a different retinoscopist (Ms K. Durden), which shows a similar degree of agreement.

We have also examined the reliability of photorefraction. A group of 69 infants were photorefracted twice, with a brief interval, and the photographs independently measured by different individuals. Fig. 8 shows the results: correlation of $r=0.91$ indicates high reliability. Differences over $0.5 \mathrm{D}$ are rare: they occur most often for large refractive errors where the blur circles are very diffuse and consequently difficult to measure. For use in screening the detection that a refractive error is large is what is most important; its exact magnitude may have to be established by other methods on follow-up.

\section{Refractive screening programme}

The age of 6-9 months was selected for initial screening on the grounds $(a)$ that Ingram et al. ${ }^{9}$ suggest, on the basis of screening at age 1 year, that an earlier screening might be preferable; $(b)$ that attendance at a screening programme was likely to be best at an age when parents were still in frequent contact with various child health services; $(c)$ that this was found to be an age when infants' behaviour and visual attention made rapid photorefraction easy.

The initial proposal was approved by the local ethical committee and involved the co-operation of 
personnel from the Department of Ophthalmology, Addenbrooke's Hospital, and Cambridge Department of Community Health. The consent of general practitioners and health visitors for screening of their patients was also obtained.

\section{STUDY POPULATION}

All infants aged between 6 and 9 months with addresses in the City of Cambridge were identified from the Community Medicine Child Health register and were sent an appointment for vision testing at one of 8 child health clinics within the city. Infants who failed to attend the first appointment were sent a second appointment. Between March 1981 and October 1982, 1096 infants were tested. In addition to this screening population 78 children were also tested who fell outside the geographical area or the age range for the programme (they were aged up to $2^{1 / 2}$ years) but for whom health visitors, general practitioners, or parents expressed concern about a possible vision problem ('external referrals').

VISION TESTS AT THE CLINIC

The community orthoptists and personnel from the Visual Development Unit carried out the tests and subsequently checked the photographs. On entering the clinic the infant's medical details were checked and a parent or guardian questioned about family eye history, in particular the incidence of strabismus or amblyopia in the child's parents or siblings. An orthoptic examination was carried out. This included examination of the corneal reflexes, cover test, and ability to overcome 20-dioptre prisms. Any child who showed an anomaly in these tests was retested on follow-up and if shown to abnormal was seen at the hospital clinic. Following the orthoptic examination 1 drop of $1 \%$ cyclopentolate hydrochloride was then placed in each eye and a 40 min waiting time observed for the drops to produce cycloplegia. The effect of the drops and the nature of the photographic tests were explained to all parents by the orthoptist.

After the waiting time each infant was photorefracted, as described above under 'Materials and method'. If there was any doubt about the child's fixation towards the camera on any photograph, it was immediately repeated. A record of the order of photographs was taken throughout the session. Individual children were identified by a name tab held above the child's head in the pupil photograph. On completion of photorefraction the parents or guardians was told that if they did not receive notification of a second check in 2-3 weeks they could assume that no refractive error had been detected and at this present time there was no suspicion of a squint or poor vision. They were also told that the cycloplegia would gradually decay, with the pupils return- ing to their normal size within approximately 24 hours. Any child who was found to need a follow-up check was seen approximately 4 weeks after the initial appointment.

It has proved practical for 2 people working together to screen up to 30 infants in a 3-hour session (including waiting time), and larger numbers have been tested on occasions. An orthoptist working alone could be expected to screen 15 infants in a session.

ANALYSIS OF PHOTOREFRACTION

From the empirical calibration table, previously discussed, we set cut-off sizes for the blur circles for each value of pupil size. If on a given photograph the blur circle exceeded the criterion in size, the infant was referred for a follow-up check because of a significant refractive error. The cut-offs were set so that the following groups were followed up:

(a) Any infant with a hypermetropic value exceeding $+3.5 \mathrm{D}$ in one or more axes, but not exceeding the $1.0 \mathrm{D}$ of difference between equivalent axes of the 2 eyes. These infants are called 'large hypermetropes (without significant anisometropia).'

(b) Any infant with one or more axes showing a myopic refraction (relative to the camera position at $75 \mathrm{~cm}$ ) and not exceeding 1.0 D difference between equivalent axes of the 2 eyes. These infants are called 'myopes (without significant anisometropia).'

(c) Any infant who showed the equivalent of more than 1.0 D of difference between equivalent axes of the 2 eyes. These infants are called 'anisometropes.'

(d) A 'control' group of infants were also followed up, there being one control infant for each of the infants in $(a)$. A control infant was selected on the basis of being the next infant to be photorefracted, after each large hypermetrope, who was not in groups $(a),(b)$, or $(c)$.

\section{FOLLOW UP EXAMINATION}

These tests were carried out at the Visual Development Unit. For each infant: (a) Medical details and family eye history were checked. (b) An orthoptic examination was undertaken by different personnel from those who performed the initial examination in the clinic. (c) An assessment of binocular acuity was made by a modification of the preferential looking technique. (d) Ability to accommodate freely and accurately at a distance of $75 \mathrm{~cm}$ was tested by photorefraction by the standard procedure but without cycloplegia. The test was carried out in a dimly illuminated room with the infant's attention being attracted to the camera operator by an illuminated rattle. (e) One drop of $1 \%$ cyclopentolate hydrochloride was then placed in each eye to produce cycloplegia. 40 minutes later photorefraction was 
repeated in exactly the same way as in the clinic. $(f)$ A senior registrar in ophthalmology carried out an ophthalmological examination of the fundus of each eye. No pathology was detected in any of the children followed up. (g) An ophthalmic optician carried out retinoscopy on each infant without knowing the previous photorefractive results of the child, the reason for referral, or whether the child was a 'control.' In this paper we shall concentrate on the retinoscopic findings and their relation to the photorefraction in the screening test.

\section{Results}

\section{ATTENDANCE}

The numbers of infants sent appointments remained fairly constant month by month throughout the pilot programme. The attendances varied from clinic to clinic between $62 \%$ and $80 \%$, with the average at $71 \%$. From informal checks it was estimated that between $5 \%$ and $10 \%$ of those sent appointments did not receive them due to high mobility in certain parts of the population and therefore incorrect addresses on the computer records. These good attendance rates reflect the concern shown by parents for their children's vision.

REFRACTIVE ERRORS DETECTED

A total of $121(11 \%)$ of the infants screened were referred for follow-up. The first 4 rows of Table 1 show how these were divided among the categories defined above in the section 'Analysis of photorefraction'. Three infants (all in the hypermetropic group) failed to attend follow-up, in 2 cases because they had moved from the area.

Table 1 also includes (last 5 rows) the children who were 'external referrals' to the screening programme. A higher proportion of these $(23.1 \%)$ required follow-up, indicating that in these cases there was some basis for the parent or health visitor's concern. However, it is notable that three-quarters of these children showed no detectable visual error. A substantial number of these were pseudostrabismic due to broad epicanthi, and so the facility of referring them to a community screening programme may be supposed to have reduced the load on hospital outpatient eye clinics.

A further 36 children were recalled for photorefraction because their first set of photographs could not be interpreted owing to technical faults. This became rarer as the project proceeded and operators became thoroughly familiar with the camera equipment.

\section{COMPARISON OF PHOTOREFRACTION AND RETINOSCOPY}

The right-hand columns of Table 1 show the results of retinoscopic refraction of the followed up groups. In general the photorefractive findings were closely confirmed. The only significant discrepancy (less than

Table 1 Outcome of screening and follow-up.

\begin{tabular}{|c|c|c|c|c|}
\hline \multirow{2}{*}{$\begin{array}{l}\text { Screening outcome } \\
1096 \text { infants from } \\
\text { screening population }\end{array}$} & \multirow[b]{2}{*}{$55(5.0 \%)$ hypermetropic } & \multicolumn{3}{|c|}{ Follow-up outcome } \\
\hline & & 52 followed up & $\begin{array}{r}50 \\
2\end{array}$ & $\begin{array}{l}>+3 \cdot 5 \mathrm{D} \text { on retinoscopy } \\
+3 \mathrm{D} \text { to }+3 \cdot 5 \mathrm{D} \text { on retinoscopy }\end{array}$ \\
\hline & $49(4 \cdot 5 \%)$ myopic & & $\begin{array}{r}6 \\
43\end{array}$ & $\begin{array}{l}>-3 \text { D on retinoscopy } \\
-0.5 \mathrm{D} \text { to }-3 \mathrm{D} \text { on retinoscopy }\end{array}$ \\
\hline & $14(1 \cdot 3 \%)$ anisometropic & & $\begin{array}{l}7 \\
4 \\
3\end{array}$ & $\begin{array}{l}>1 \mathrm{D} \text { anisometropia on retinoscopy } \\
0.5 \text { to } 1 \mathrm{D} \text { anisometropia on retinoscopy } \\
\text { no anisometropia on retinoscopy }\end{array}$ \\
\hline & $\begin{array}{l}3(0 \cdot 3 \%) \text { strabismic on } \\
\text { orthoptic tests }\end{array}$ & & 3 & confirmed on orthoptic follow-up \\
\hline & $975(88 \cdot 9 \%)$ normal & 52 controls followed up & $\begin{array}{r}51 \\
1\end{array}$ & $\begin{array}{l}\text { normal on retinoscopy } \\
\text { small myope on retinoscopy }\end{array}$ \\
\hline \multirow{4}{*}{$\begin{array}{l}78 \text { referrals from outside } \\
\text { screening population }\end{array}$} & $7(9 \cdot 0 \%)$ hypermetropic & & 7 & $>+3 \cdot 5 \mathrm{D}$ on retinoscopy \\
\hline & $6(7 \cdot 7 \%)$ myopic & & 6 & myopic on retinoscopy \\
\hline & $3(3 \cdot 8 \%)$ anisometropic & & $\begin{array}{l}1 \\
2\end{array}$ & $\begin{array}{l}>1 \mathrm{D} \text { anisometropia on retinoscopy } \\
0.5 \text { to } 1 \mathrm{D} \text { anisometropia on retinoscopy }\end{array}$ \\
\hline & $\begin{array}{l}2(2 \cdot 6 \%) \text { strabismic on } \\
\text { orthoptic tests } \\
60(76 \cdot 9 \%) \text { normal }\end{array}$ & & 2 & $\begin{array}{l}\text { confirmed on orthoptic } \\
\text { follow-up }\end{array}$ \\
\hline
\end{tabular}


$1 \%$ of the screened population) are anisometropias seen in photorefraction, which appear smaller or nonexistent in retinoscopy. These could be due to either off-axis errors in initial photorefraction or to the greater difficulty of identifying differences between the eyes in retinoscopy as compared with photorefraction, where both eyes appear on the same photograph. In some cases at least off-axis errors were probably responsible, since the difference was not apparent when photorefraction was repeated at follow-up.

One infant in the control group (2\%) was found to have a refractive error (small myope) on follow-up: this can be taken as some indication of the low rate of 'false negatives' from this screening procedure.

The orthoptic problems identified in initial screening were confirmed on follow-up.

\section{Discussion}

This study has shown that photorefraction provides a feasible, rapid, and reliable means for the refractive screening of a general population of infants.

We find that about $6 \%$ of infants aged 6-9 months have large refractive errors $(4.6 \%$ hypermetropia over $+3.5 \mathrm{D} ; 0.5 \%$, myopia over $-3 \mathrm{D} ; 0.6 \%$, anisometropia over $1 \mathrm{D})$. Previous literature on the distribution of refractive error does not seem to include this age group. Studies of newborns ${ }^{15} 16$ have reported that $25 \%$ show hypermetropia over $3 \mathrm{D}$ and a negligible proportion show significant myopia, although there are wide variations between reports. Ingram, ${ }^{8}$ screening infants at 1 year, found that $1 \%$ showed hypermetropia over $+3.5 \mathrm{D}$ and $2 \%$ myopia over $-1.25 \mathrm{D}$ (he gives no figures for greater myopia). Our figures are intermediate between these, supporting the idea that refractions on average become less hypermetropic over the first year of life (although this does not necessarily hold for individual refractions).

While myopia over $-3 \mathrm{D}$ is rather rare in this age group, its identification is worthwhile, since it provides the opportunity to correct, where appropriate, an error which may be impairing the use of vision in an important period of a child's general development. Congenitally high myopes may be at risk of developing severe retinal disease; this is another reason for early detection. Lesser degrees of myopia $(0.5$ to $3 \mathrm{D})$ are relatively common (almost $5 \%$ ). Further follow-up of these latter children will show whether these refractions follow a rule of 'emmetropisation' or increase with the general trend away from hypermetropia. It should be noted that many of these refractions are astigmatic, and while the common astigmatism of infancy declines rapidly with age $^{17}$ we do not yet know whether refraction tends to that of the more myopic or more hypermetropic axis.

Marked anisometropia is not very common in our sample, but we regard it as important to detect, since, if uncorrected through infancy, it is likely to lead to amblyopia.

Hypermetropia is the commonest refractive error of infancy, and the usefulness of refractive screening depends to a large degree on the value of detecting hypermetropia early. The identification of a group of infant hypermetropes in this study will allow longitudinal study of changes in their refractive errors, their risk of esotropic strabismus, and the efficacy of possible preventive measures.

We thank Dr Robert Ingram for collaborating with us in our initial comparison on retinoscopy with photorefraction. We are grateful to Dr G. Gresham, Mr L. Pegginton and Mr A. Bampton, Department of Community Health, Cambridge Health Authority, for their cooperation in setting up the screening programme. We thank $\mathrm{Dr}$ David Allen for carrying out many of the ophthalmological examinations; the orthoptists, in particular Heather Madley, Mary Hill, Debbie Arnold, and Ruth Banks, for carrying out the orthoptic examinations and much of the photorefraction; Carol Evans and Claire Towler for their clerical organisation; Elizabeth Pimm-Smith, Jackie Day, and John Wattam-Bell from the Visual Development Unit for their assistance, and many general practitioners and health visitors for their co-operation and support.

This research was supported in part by the Medical Research Council. We are grateful to Smith and Nephew Pharmaceuticals Ltd. for a donation of cyclopentolate, and to Kodak Ltd. for a donation of photographic materials. Kim Durden was supported by a grant from Pilkingtons (PE) Ltd.

\section{References}

1 Nordlöw W, Joachimsson S. A screening test for visual acuity in four year old children. Acta Ophthalmol (Kbh) 1962; 40: 453-62.

2 Kellmer-Pringle ML. Butler NR, Davie R. 11000 Seven-yearolds. First report of the National Child Development Survey. London: Longmans, 1966.

3 Graham PA. Epidemiology of strabismus. Br J Ophthalmol 1974; 58: $224-31$.

4 Oliver M, Nawratzki I. Screening of pre-school children for ocular anomalies. Br J Ophthalmol 1971; 55: 462-6.

5 Amigo G. Pre-school vision study. Br J Ophthalmol 1973; 57: 125-32.

6 Köhler L, Stigmar G. Vision screening in 4 year olds. Acta Paediatr Scand 1973; 62: 17-27.

7 MacLellan AV, Harker P. Mobile orthoptic service for primary screening of visual disorder in young children. $\mathrm{Br}$ Med J 1979; i: 994-5.

8 Ingram RM. Amblyopia: the need for a new approach? $\mathrm{Br} \mathrm{J}$ Ophthalmol 1979; 63: 236-7.

9 Ingram RM, Traynar MJ, Walker C, Wilson JM. Screening for refractive errors at age 1 year: a pilot study. $\mathrm{Br} J$ Ophthalmol 1979; 63: 243-50.

10 Duke-Elder S. Textbook of Ophthalmology. London: Kimpton, 1949: 4.

11 Atkinson J, Braddick OJ, Ayling L, Pimm-Smith E, Howland HC, Ingram RM. Isotropic photorefraction: a new method for refractive testing of infants. Doc Ophthalmol Proc Ser 1981; 30: 217-23.

12 Atkinson J, Braddick $O$. The use of isotropic photorefraction for 
vision screening in infants. Acta Ophthalmol (Kbh) 1983; 157 (suppl): $36-45$.

13 Howland H, Braddick O, Atkinson J, Howland B. Optics of photorefraction: orthogonal and isotropic methods. J Opt Soc Am in press.

14 Howland HC. Howland B. Photorefraction: a technique for study of refractive state at a distance. J Opt Soc Am 1974; 64: $240-9$.
15 Borish IM. Clinical refraction, 3rd ed. Chicago: Professional Press, 1970.

16 Baldwin WR. Clinical research and procedures in refraction. In: Hirsch MJ, ed. Synopsis of the refractive state of the eve. Minneapolis: Burgess, 1965.

17 Atkinson J, Braddick O, French J. Infant astigmatism: its disappearance with age. Vision Res 1980; 20: 891-3. 